\title{
The Use of IT to Increase Nutritional Awareness in Young Children
}

\author{
Nayna Patel, Simon Kent and Sarunjit S. Rai \\ Department of Information Systems and Computing, Brunel University, Uxbridge, Middlesex, UK
}

\begin{abstract}
It has been well documented that obesity amongst young children is on the increase. By the age of 5 the level of obesity is alarming and is much greater than expected in comparison to the national standards. To address this problem, an overall health programme is required encompassing healthy eating and physical activity. However, a radical change of this nature has not shown any long-term benefits and can result in a negative attitude from the child. Therefore, more subtle ways of increasing awareness in children about healthy eating were thought to be the key. Since children are spending an increasing amount of their free time playing computer games, it was thought that this would be a good way of introducing them to healthy eating. Therefore, a prototype system is developed and tested to identify whether IT can be used to raise nutritional awareness in young children. The results show that the increase is marginal, but the system did encourage discussion about the effects of food amongst a group of children aged between 4-5.
\end{abstract}

Keywords: learning, computer-aided learning, obesity, nutrition, IT and learning.

\section{Introduction}

Obesity has already reached unmanageable proportions in the United States and it appears that the UK is set to follow this trend. Not only is obesity a problem in itself, it can act as a trigger to many other health and psychological problems, placing a heavy burden on the NHS in terms of cost and provision. Many initiatives to address this have been undertaken, but unfortunately have not delivered any significant improvement in the long term. Hence, surgery remains the most successful method of tackling obesity [1]. However, treating the problem is not seen as the most appropriate solution, and, instead, prevention is the preferable approach [2]. In taking this stance, it has been identified by many that the root of obesity stems from childhood $[3,4]$. Therefore, it would appear evident to attempt to prevent the path of obesity being established in the first place. Furthermore, educating children about the importance of leading a healthy lifestyle and making them aware of the consequences if this is not achieved is thought to be the key [3].

Therefore, the purpose of this paper is to investigate the use of technology to help increase nutritional awareness in young children. The paper begins by discussing obesity and the implications of it in adulthood. This also includes a discussion of previous attempts to raise nutritional awareness using computer programs. This is followed by a description of the prototype that was designed as a result of this research. Following this, an evaluation of the prototype is provided with regards to the aim of increasing nutritional awareness in young children.

\section{Childhood obesity}

In simple terms, obesity can be described as a condition where weight is at a level such that it is detrimental to health [5]. In the past, obesity was considered to be a result of genetics, however, more recently it has been attributed to living a certain kind of lifestyle [6]. This type of lifestyle consists of a combination of a lack of physical activity and eating a poor diet consisting of foods that are rich in saturated fats. The potential consequences of leading such a lifestyle are heart disease, hypertension, diabetes [4], high blood pressure, stroke and cancer 
[7] in adulthood, eventually leading to premature morbidity [8]. In childhood, obesity can increase the risk of premature illness and death in life and, in general, obese children tend to reach puberty many years before healthy children. The psychological effects may include low self-esteem, sadness, loneliness, nervousness, high-risk behaviour, [9] and a negative self-image [10]. Many attempts have been made at both treatment and prevention. However, unfortunately as of yet, an effective long-term solution has not been found $[8]$.

The reason why existing initiatives have proved to be unsuccessful may be because many involve a drastic change that can cause disruption to a child's life and may also be difficult for them to maintain motivation for. Furthermore, these initiatives revolve heavily around direct intervention, either by the family or school. For instance, the former would involve a family changing their lifestyle to include eating a more healthy diet, the intention being that a change made by the whole family would be easier to adopt and would decrease the likelihood of a child comfort eating [1]. According to Ebbeling et al., [1] this approach did produce positive long-terms results in motivated children, however the overall results were deemed as disappointing.

There are many examples of school-based programmes. For example, an initiative called "Grab 5" managed by Sustain, the alliance for better food and farming is aimed at primary schools in England. Grab 5 is about encouraging their pupils to eat more fruit and vegetables. One of the ways that Grab 5 has tried to tackle obesity in schools is by having "fruit tuck shops" where pupils can only purchase fruit for a snack at play times in replacement of crisps, sweets and chocolate. Another scheme being run in schools is the National School Fruit Scheme (NSFS). This scheme originally started in the West Midlands in April 2002 and has now come to London. Its goal is to supply each pupil with one piece of fruit per day. The intention is for the whole country to be involved by 2004 . Among other schemes in other countries is, for example, 'Planet Health'. This is an interdisciplinary curriculum that is aimed at decreasing dietary fat consumption, increase consumption of fruits and vegetables, promote physical ac- tivity, and limit television time [1]. Another one was The APPLES (Active Program Promoting Lifestyle Education in Schools). It involved nutrition education, provision of healthy lunches, a fitness program, improved playground facilities, and extracurricular activities. There were some positive results from these initiatives but the overall outcome was deemed to be unsuccessful [1].

In each of these instances, and as the term 'intervention' suggests, the approach of the programme can be viewed as something that is forced upon the children. These may be considered to be rather restrictive, preventing children from having freedom of choice. Furthermore, it is possible that the children would simply revert back to old habits once they are out of the context of where the 'programme' is implemented, when they move to a new school for instance or visit their local supermarket. For instance, replacement of the normal tuck shop with a fruit only, does not provide the children with freedom of choice. By removing the unhealthy foods the children are not given the opportunity to learn about and understand the reasons why the healthier option is better than the unhealthy one.

Perhaps a better approach would be to educate children about the importance of leading a healthy lifestyle and making them aware of the consequences if this is not achieved. According to Elrick et al., [3] the key lies in educating young children in good nutritional practices. However, simply presenting children with a series of facts and expecting them to learn and apply them is perhaps asking too much. In 1995 Rickard et al., [11] suggested the play approach to learning as an alternative way of educating young children about nutrition and fitness. According to Rickard et al., [11] the concept of this approach is based on using a child's natural instinct to play to enhance knowledge, understanding, and skill in establishing good eating habits. It is believed that educating children through their everyday play offers them the opportunity to make choices, for which they are able to take responsibility and, in turn, this is thought to provide them with a sense of ownership for their own actions and bodies [11]. Although the play approach to learning appears to make common sense, and even though less than 
10 years have elapsed since its proposal, the context for which the approach was intended has drastically changed to one where computer games are one of the key 'play' items for young children. Therefore, it would be interesting to apply this approach to today's concept of play.

Initially, this would appear to be rather contradictory since it is quite common for sedentary behaviour such as TV viewing and playing computer games to be attributed to causing obesity. Studies have shown that there seems to be some association between television viewing and obesity in adults, however, the results for television viewing and children are mixed [12]. The results from research with regards to computer games is still in its infancy and a great deal more research is required in the area. However, research conducted thus far has not produced any significant results [12]. It has been suggested that a possible reason for this could be attributed to the fact that many children are active when playing computer games, mimicking the equivalent of what might be considered as mild exercise [12]. Therefore, using a computer game to educate children about nutrition may prove to be beneficial.

Although the concept of using computer games as a learning tool for young children is not a particularly novel one, this may prove to be the reason why this is a successful method. As mentioned earlier, previous initiatives have been quite drastic in their approach and tend to cause a fair amount of upheaval, especially in a young child's life. Therefore, using a medium that is already a major part of their daily activities could potentially be the key. Obviously, this would not provide a solution for obesity and is not intended in this vein. However, it is perceived as more of a tiny stepping-stone in the right direction and may prove of benefit in the long-term. Using a computer game for teaching children about nutrition is advantageous in comparison to other methods since it enables interactivity and the ability to immediately view the results of actions. This is particularly important in the context of obesity because, with the exception of surgery, the results of any initiatives to tackle obesity can take months or even years to become apparent, making it difficult for children to understand the benefits of living a healthy lifestyle. Interactivity is important since it enables children to learn that they are in control and the outcome of the game is dependant on their actions. It is anticipated that they may apply this to themselves with the understanding that if they eat healthily, they live healthily.

Further justification for using computer games for health education, whether intentional or unintentional, computer games are already being used as a way of increasing physical activity. These come in the form of dance mats that are placed on the floor and can be linked up to the computer game. The idea is that whilst music is playing the computer screen specifies a series of dance steps. The aim is for the player to step/jump on the correct arrows that are placed on the dance mat in time to the music. It is normal for a vast selection of songs to be available, with varying speeds of rhythm. Therefore, whilst someone is playing on the dance mat, they carry out a fair amount of physical activity. This was obviously recognised by the marketing companies that games have recently been produced as actual fitness programmes. It appears that research as to the impact of dance mats is limited, although this is unlikely to be the case for very long.

Returning to the theoretical aspect of health education, a number of initiatives involving using computers to teach children about healthy living and eating have already been developed by the Foods Standards Agency and the British Heart Foundation. These organizations have been setup to "protect the public health and consumer interests in relation to food" and "play a leading role in the fight against heart disease so that it is no longer a major cause of disability and premature death" respectively. Both of these organizations are non-profit making and therefore are deemed to have the public interest in mind. Therefore, if they are using computer games to educate children about various healthrelated issues then this would appear to be a viable option for teaching children about nutrition. However, prior to proceeding with this, the following section looks at some of the games available through these organizations websites. 


\subsection{Existing Websites}

On their website, the Foods Standards Agency has developed an 'interactive tools' area which has various links to calculators, games, quizes and education. Under the games section is a program aimed at 7-10 year olds whereby children can learn about food hygiene. This is achieved by presenting the child with a quiz containing various questions about food hygiene. Figure 1 shows an example of a question screen. The child progresses through the quiz, attempting to answer correctly as many questions as possible. The concept of this program is good and encourages the children to learn facts about food hygiene. However, it may mean the children simply memorise the answers without actually being able to understand the material and, more importantly, without being able to apply it to themselves.

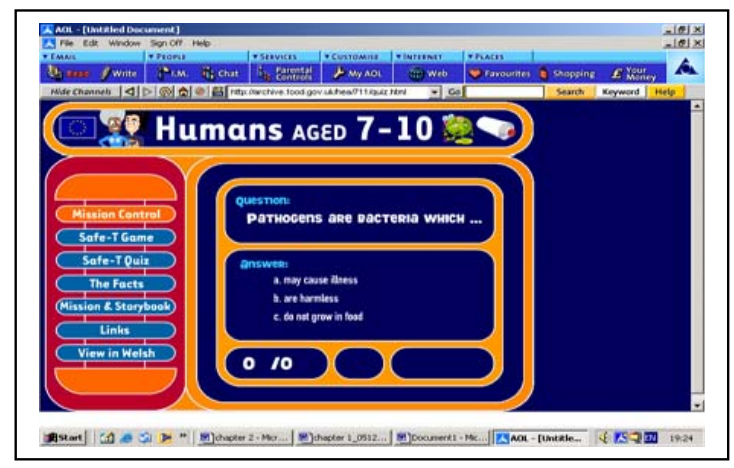

Fig. 1. A question from food hygiene program.

The British Heart Foundation has developed a program called 'Nutrition Mission' aimed at 68 year olds. Nutrition Mission is based on a character called Artie Beat. Artie Beat prompts the child to feed him and makes the child shop for food for each of his meals. The child is then requested to store the food in a cupboard that contains five shelves. Each shelf is individually labelled with a particular food type including: milk and diary; bread, cereal and potatoes; fruit and vegetables; meat, fish, etc; foods containing sugar and fats. Figure 2 displays an example of the shelves in Nutrition Mission. If Artie Beat is fed a healthy diet then he smiles, indicating that he has been fed the correct foods and the child is given the option to play more games. However, if Artie Beat is fed an unhealthy diet then he displays an unhappy face and the child is unable to play more games.

This program is better than the previous one in that it enables a child to gain some idea of the effect that certain foods have on a person. However, categorisation of the foods using the shelving system was considered to be rather misleading in places. For instance, some foods that the program categorised as meat, such as chicken curry, obviously contains meat, however this particular dish is also high in fat. Although children are able to see a description of each item if they wish, a description of fat content is not provided. Consequently children could be misled to believe that the item is a meat product, which is fine to eat, but they would not learn that it is also high in fat. As previously mentioned, fat is a major contributory factor in a child becoming obese and therefore this moves away from what is trying to be achieved. Another example is the case of the fruit flavoured drink that was classified under the 'fruit and vegetable' category. In some cases these types of drink do contain fruit extracts, but they are minimal and these drinks are predominantly made up of sugar. Consequently, a child may misinterpret this to mean that fruit flavoured drinks are healthy.

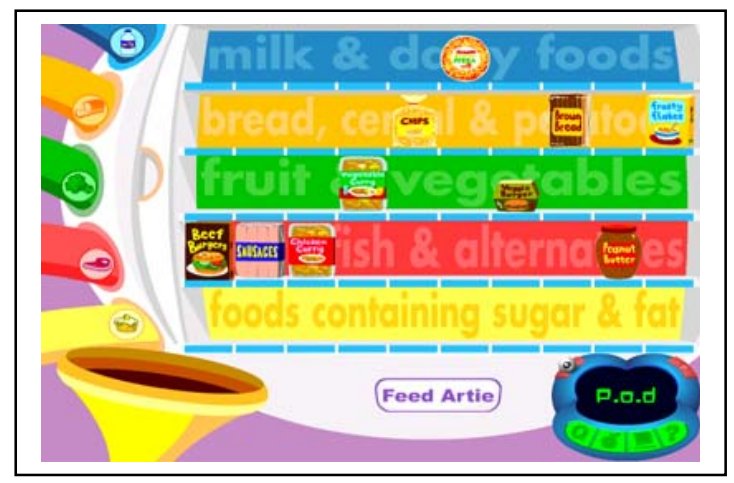

Fig. 2. Shelves in Nutrition Mission.

In both cases, these programs are a positive step towards educating children about healthy eating. However, it is obvious that both are still in their infancy and a great deal more work is required. Furthermore, it has been identified that obesity is evident in children as young as the age of $5[1,13,14]$. The Food Standards Agency program is aimed at 7-10 year olds and Nutrition Mission at 6-8 year olds. Consequently, 
it is likely that the path to obesity has already been established and then this becomes a case of treatment rather than prevention. Therefore, a game aimed at a younger target group is required. The following section describes a prototype that was developed and tested to see if technology can be used to increase nutritional awareness in young children.

\section{Child Nutrition Prototype}

Following from the concept of Artie Beat in Nutrition Mission, the system was developed using the idea behind the Tamagotchi, an interactive pet in a key chain designed by the Japanese to help their children to learn about looking after a pet. The intent for the nutrition program was that children would take responsibility of a character they have chosen, by feeding and exercising it. The effects of this would be demonstrated by the character's size. For instance, if the character was fed a poor diet, then it would increase in size as shown in Figure 3. If the character was fed a healthy diet and well exercised, then it would remain the same. The reason for choosing character size was mainly due to the age of the target group being so young i.e. 4-5 year olds. It was thought that the change in the characters' size would be the simplest way of demonstrating the impact of the food that was eaten.

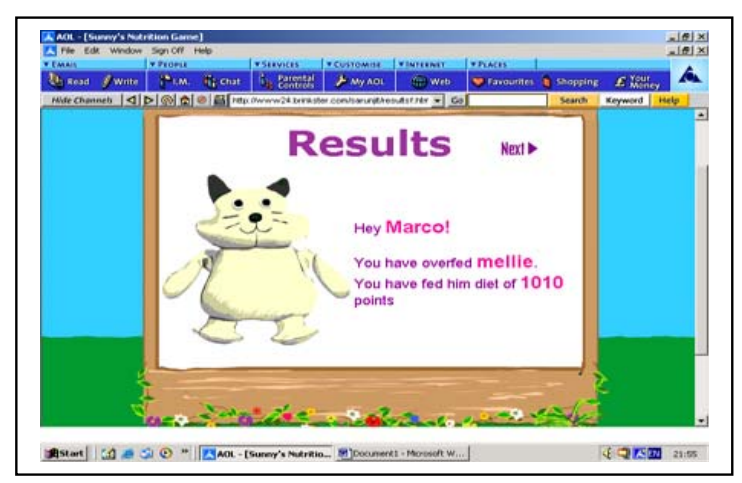

Fig. 3. An example of an overfed character.

To begin with, children are presented with a welcome screen showing all the characters in the program. As shown in Figure 4, in the following screen they are asked to choose the character they would like to play the game with.
Once they have selected a character they give it a name, the purpose of which is to increase the likelihood of them identifying with the character and taking responsibility for it. Each character also has a humorous description associated with it to help the child build a bond with the character.

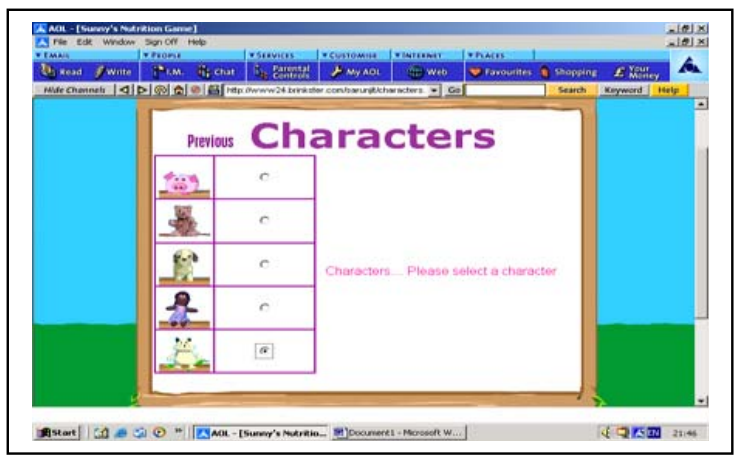

Fig. 4. Choice of Character.

Once the character has been established, the children can begin playing the game. They are required to feed their character breakfast, lunch and dinner. Examples of the choices for breakfast are displayed in Figure 5. In order to maintain the game element for the program, icons are used to represent the different types of food available. The children are required to select what they would like to feed their character for breakfast. As the character is fed each item, the child is able to view what affect that particular food produces i.e. the child is able to immediately view the results. A similar process takes place for lunch and dinner, only the choices of food are different. Allowing the child to select the character and select what food their character is fed, increases the level of interactivity that takes place.

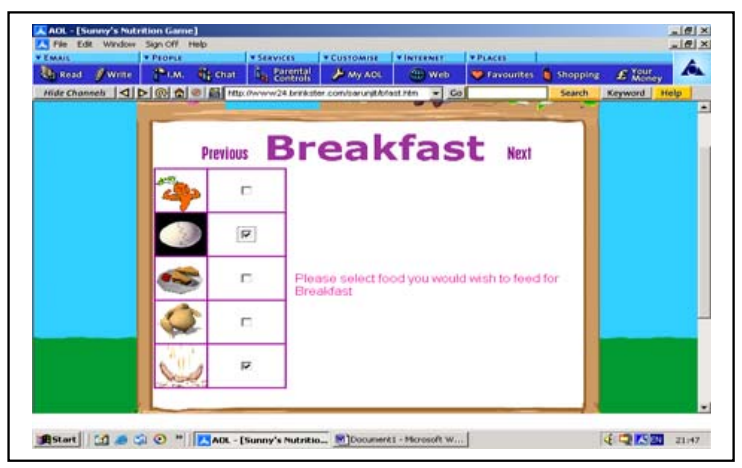

Fig. 5. An example of the breakfast menu. 
Once the character has been fed the three meals the child is able to view the overall results. If the character has been fed a good diet, the character appears at normal size, thanking and congratulating the child for feeding it a good diet. If the character is fed a poor diet, then a screen similar to the one shown in Figure 3, where the character has increased in size, is displayed. In both cases the child is displayed with a screen representing a traffic light system, as shown in Figure 6.

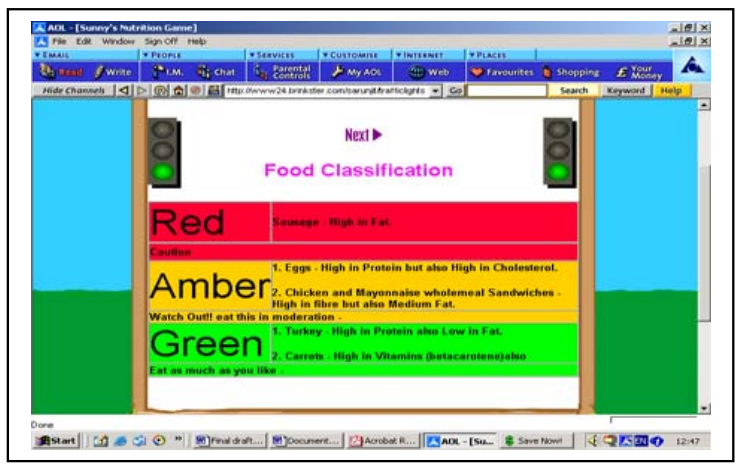

Fig. 6. Foods classified using a traffic light system.

The basic concept is that the foods children have fed to their character with are classified using the traffic lights - a concept that they should already be familiar with at this age. Foods in the red area indicate that the child should be cautious, amber indicates foods that should be eaten in moderation and green indicates healthy foods that can be eaten in relatively high quantities. For instance, if the character was fed with sausages, this would be reflected in the red area along with the information that this particular food has a high fat content. Food such as eggs would be displayed in the amber area with the information that, although they contain protein, they are also high in cholesterol. The vegetable carrots would be displayed in the green area of the traffic lights system with the message that this food is high in vitamins and can be eaten in any quantity. If children were not successful in feeding their character a good diet, they are given the opportunity to go back and play the game again, using the knowledge they are anticipated to have acquired. The following section describes the initial results from the testing of the prototype.

\section{Evaluation of Prototype}

The prototype was tested with a group of 13 four to five year old children. Prior to conducting the testing of the system, the children were asked to complete a basic questionnaire in order to establish what their nutritional knowledge was to begin with. Ideally, an existing method of teaching children about nutrition would have been used so that the results could be compared. However, it appears that existing initiatives are aimed at children that are above five years of age and, therefore, 'before' and 'after' tests were conducted. The questions that were used are illustrated in Table 1. Considering the very young age of the children, only five questions

\begin{tabular}{|c|c|c|c|}
\hline Questions & Potential Answers & Before & After \\
\hline 1. Is it important to eat breakfast? & $\begin{array}{l}\rightarrow \text { Yes } \\
\rightarrow \quad \text { No }\end{array}$ & $11 / 13$ & $13 / 13$ \\
\hline $\begin{array}{l}\text { 2. How many portions of fruit/vegetables should you eat a } \\
\text { day? }\end{array}$ & $\begin{array}{l}\rightarrow \quad 3 \\
\rightarrow \quad 4 \\
\rightarrow \quad 5\end{array}$ & $12 / 13$ & $12 / 13$ \\
\hline 3. Which is most healthy? & $\begin{array}{ll}\rightarrow & \text { Apple } \\
\rightarrow & \text { Chocolate } \\
\rightarrow & \text { Cake }\end{array}$ & $13 / 13$ & $13 / 13$ \\
\hline 4. What food do you prefer? & $\begin{array}{ll}\rightarrow & \text { Sausages } \\
\rightarrow & \text { Turkey } \\
\rightarrow & \text { Bacon } \\
\end{array}$ & $5 / 13$ & $10 / 13$ \\
\hline 5. Which 2 food groups should you eat the most? & $\begin{array}{ll}\rightarrow & \text { Fruit and vegetables } \\
\rightarrow & \text { Meat and fish } \\
\rightarrow & \text { Fat and sugar } \\
\rightarrow & \text { Bread, cereal and potatoes } \\
\rightarrow & \text { Milk and diary foods }\end{array}$ & $3 / 13$ & $5 / 13$ \\
\hline
\end{tabular}

Table 1. Results from testing the prototype. 
were used. Children were taken aside individually, accompanied by their class teacher, so that a familiar face was always present. Props were used in order to help them understand the questions. For instance, with the question about food groups, actual food was used and displayed in the respective groups. It took approximately 15-20 minutes for each child to answer the questions. Four weeks later, they were asked to play with the prototype, after which they took the same test. The results from the 'before' and 'after' are displayed in Table 1.

The results show a slight increase in knowledge after using the prototype. The major changes were in the response to question 4. Subsequent to using the prototype, five out of the 13 children changed their answer to the more healthy option. For instance, being asked about 'what foods they preferred' they had initially answered sausages, after playing with the prototype they selected turkey. The other stumbling block that was evident was the last question. The majority of children knew that fruit and vegetables was one of the major food groups but then specified milk and diary food as the other. After further investigation it was found that it was common for the children's parents/carers to tell them to drink their milk because it would make them strong. In the majority of cases the children answered both questionnaires similarly. However, from the responses that they provided it could be concluded that they were knowledgeable about nutrition in the first instance. It can be said that the results from the questionnaires did not provide any conclusive results, however a discussion with the group subsequent to the questionnaires being completed proved to be rather interesting.

The discussion was held with the group of 13 children and their teacher was also present. Since the program was a prototype, the purpose of the discussion was to gain an understanding of their views of the system. They appeared to find the program fun to use and they particularly liked the fact that they were able to 'adopt' a character and give it a name. The most important observation arising from the discussion was that the children were talking about how the different foods had made their character grow. Such comments included statements such as, 'If I fed Billy [the name of their character] sausages then he would grow fat but when I gave him a carrot he would get thin'. Therefore, although the quantitative data were unable to provide any significant results the fact that they were discussing the program is positive.

\section{Discussion}

This is a sensitive and quite often a controversial subject area and there are many issues arising from research such as this. Many of these are related to the medical aspect and therefore inappropriate to discuss within this paper. However, issues that relate to the IT area would be with regards to design of the interface.

For instance, is the size of the character the most suitable way of portraying healthy eating? In its current state the prototype does not accommodate the action of the character not being fed. Therefore, children could conclude that if they do not feed the character then it will not increase in size, and hence they would win the game. This could potentially exacerbate the problem of eating disorders and this is definitely not the intention of the prototype. Another consideration arising from this research is processed foods. According to the prototype, fish is healthy and may lead a child to believe that a product such as fish fingers is also healthy, without being aware of the high salt content and use of preservatives. Therefore, the manner in which information about leading a healthy lifestyle is presented is extremely important and must be taken into consideration when designing the interface.

\section{Conclusions}

Existing methods of tackling obesity have not proved to be successful in the long term. The radical nature of these initiatives may be responsible for such outcome. Therefore, this research looks to providing a stepping-stone, as opposed to a complete overhaul of lifestyle, in an attempt at informing young children about the importance and impact of leading a healthy lifestyle. The results from testing the prototype were marginal and a great deal more research is planned before the true value of such research can be accomplished. 


\section{References}

[1] EbBeling C.B, PAWlaK D.B. AND Ludwig D.S., Childhood obesity: public-health crisis, common sense cure, The Lancet (2002), Vol. 360, pp. 47382.

[2] CRAWFORD D. AND BALl K., Behavioural determinates of the obesity epidemic, Asia Pacific Journal of Clinical Nutrition (2002), Vol. 11, Iss. S8, pp. S718-S721.

[3] Elrick H., SAmaras T.T. And Demas A., Missing links in the obesity epidemic, Nutrition Research (2002), Vol. 22, pp. 1101-1123.

[4] NICKLAS T.A., YANG S.J., BARANOWSKI T., ZAKERI I. AND BERENSON G., Eating patterns and obesity in children - The Bogalusa Heart Study, American Journal of Preventative Medicine (2003), Vol. 25, No. 1, pp. 9-16.

[5] POST (Parliamentary Office of Science and Technology) Childhood Obesity, URL document wWW . parliament . uk . post, September 2003, No. 205.

[6] Moore L.L., GaO D., BradleE L., Cupples L.A., SUNDARAJAN-RAMAMURTI A., PROCTOR M.H., HoOD M.Y., SingER M.R. AND ELLISON R.C., Does physical activity predict body fat change throughout childhood?, Preventative Medicine (2003), Vol. 37, pp. 10-17.

[7] Wellman N.S. AND FrIENDBERG B., Causes and consequences of adult obesity: health, social and economic impacts in the United States, Asia Pacific Journal of Clinical Nutrition (2002), Vol. 11, pp. S705-S709.

[8] SABIN M.A., CROWNE E.C. AND SHIELD J.P.H., The prognosis in childhood obesity, Current Paediatrics (2004), Vol. 14, Iss. 2, pp. 110-114.

[9] STRAUSS R.S., Childhood obesity and self-esteem, Paediatrics (2000), Vol. 105, e15.

[10] DAVISON K.K. AND BIRCH L.L., Weight status, parent reaction, and self-concept in five-year-old girls, Paediatrics (2001), Vol. 107, pp. 46-53.

[11] Rickard K.A., Gallahue D.L., GRUEn G.E., TRIDLE M., Bewley N. AND STEEle K., The play approach to learning in the context of families and schools: An alternative paradigm for nutrition and fitness education in the 21st century, Journal of American Dietetic Association (1995), Vol. 95, No 10, pp. 1121-1126.

[12] WAKE M., HESKETH K. AND WATERS E., Television, computer use and body mass index in Australian primary school children, Journal of Paediatric Child Health (2003), Vol. 39, pp. 130-134.

[13] Rudolf C.J., SAHOta P., BARTH J. AND WALKeR J., Increasing Prevalence of Obesity In Primary School Children; Cohort Study, British Medical Journal (2001), Vol. 322, pp. 1094-1095.
[14] Reilly J.J., Dorosty A.R. AND EMmetT, P.M., Prevalence of overweight and obesity in British Children: cohort study, The British Medical Journal (1999), Vol. 319, pp. 1039.

Received: July, 2004 Revised: August, 2004 Accepted: August, 2004

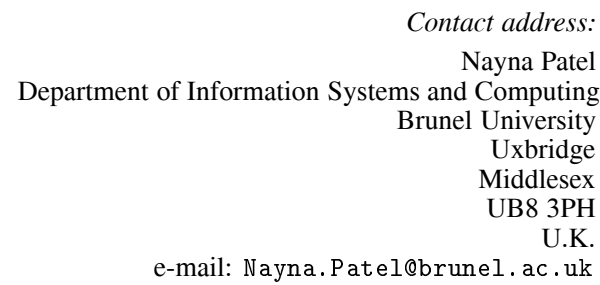

NAYNA PATEL is a lecturer in the Department of Information Systems and Computing at Brunel University, UK. Her research interests include computer assisted learning, ICT, and education.

SIMON KENT is a lecturer in the Department of Information Systems and Computing at Brunel University. His research interests include ICT and educational software.

SARUNJIT S. RAI is a researcher in the Department of Information Systems and Computing at Brunel University. His research interests include child nutrition and software interfaces. 